\title{
Possibility of Piezoelectric Sensor to Monitor Onshore Pipeline in Real Time Monitoring
}

\author{
Nurhadi Siswantoro ${ }^{1}$, Aydin Doğan², Dwi Priyanta ${ }^{3}$, Muhammad Badrus Zaman ${ }^{4}, \operatorname{Semin}^{5}$
}

(Received: 27 February 2019 / Revised: 18 March 2019 / Accepted: 26 March 2019)

\begin{abstract}
Transportation oil and gas mostly used pipelines transportation. Pipeline has the possibility to experience defects during operations such as general corrosion, fatigue, crack, and others. Defects that occur in the pipeline during operation have serious impact to environment, human, property, etc. Awareness of the importance of conducting pipeline monitoring and safety issues for workers and residents around the pipeline site, emphasizes the importance of developing a technology for conducting pipeline monitoring activities in real time. The new technology for detecting metal defects is by using piezoelectric material as sensor. Based on laboratory scale, piezoelectric sensor can be applied to monitor pipeline defect. However, it is necessary challenges to scaling up in real application are following: (1) financial investment, (2) human behavior surrounding pipeline area, (3) receiving signal in long distance, (4) protection of piezoelectric sensor, (5) combination survey for future development.
\end{abstract}

Keywords-Defect, Piezoelectric, Pipeline, Real Time Monitoring

\section{INTRODUCTION}

$\mathrm{F}$ ossil energy is still the main choice for fulfilling

energy needs, within energy of oil 33\%, natural gas 23\% and coal 28\% from total energy sources. Many companies are subjecting in the refining, petrochemical, exploration and production industry [1]. Particular in oil and gas company, mostly transportation oil and gas use pipelines transportation. Pipeline is expected to generate profits from oil and gas transportation to support the national economy [2]. Pipeline has the possibility to experience defects during operations such as general corrosion, fatigue, crack, and others. Defects that occur in the pipeline during operation have serious impact to environment, human, property, etc. [3].

In Indonesia, companies involved in the oil and gas processing industry must inspect any equipment based on national rules and regulations as stated in the Minister of Energy and Natural Resources Regulation No. 18 of 2018 [4]. Inspection is needed to monitor physical condition of the pipeline and equipment. From the inspection activities, maintenance and operation efforts can be arranged as well as possible damage control and predictions of repairs or replacements. Periodic inspections that are expected to determine the condition of damage so that it can be the basis for the selection of maintenance and repair methods. The

Nurhadi Siswantoro, Department of Marine Engineering, Institut Teknologi Sepuluh Nopember, Surabaya 60111, Indonesia, Email: nurhadi@ne.its.ac.id

Aydin Doğan, Department of Material Science and Engineering, Eskişehir Teknik Üniversitesi, Eskişehir, Turkey, Email: adogan@eskisehir.edu.tr

Dwi Priyanta, Department of Marine Engineering, Institut Teknologi Sepuluh Nopember, Surabaya 60111, Indonesia, Email: priyanta@its.ac.id

Muhammad Badrus Zaman, Department of Marine Engineering, Institut Teknologi Sepuluh Nopember, Surabaya 60111, Indonesia, Email: drus_zaman@yahoo.com

Semin, Department of Marine Engineering, Institut Teknologi Sepuluh Nopember, Surabaya 60111, Indonesia, Email: seminits@gmail.com response that occurs in the pipeline defect can be: (1) shut down and replace parts that have defects; (2) Inservice repair, both in the form of temporary and permanent repair. If this option is chosen, then the inservice repair procedure must be carefully planned and the risks that might occur must be minimized; (3) Reducing operational pressure [3].

In general, the method used in pipeline monitoring is time based monitoring. The frequency of time based monitoring depends on the type of method and equipment used for inspection. Patrol activities to monitor pipeline conditions carried out by air or land surveillance. Air surveillance using helicoter or drones can reach area that has potential damage. While detailed information can be observed by the land survey using motor cycle or walking. The activities of air or land survey can only update information about damage due to third-party. However, for structural damage due to internal and external corrosion can be checked through ultrasonic test [5]. Types and period of survey are shown in Table 1.1.

Today, awareness of the importance of conducting pipeline monitoring and safety issues for workers and residents around the pipeline site, emphasizes the importance of developing a technology for conducting pipeline monitoring activities in real time. In addition, the new technology is expected to reduce operational costs and maintenance of pipeline monitoring.

The new technology for detecting metal defects is by using piezoelectric material [6]. The piezoelectric materials for manufacturing ultrasonic transducers are as follows: Bismuth titanate (BIT) or modified bismuth titanate (MBIT), lithium niobate (LiNbO3) and Lead Zircornate Titanate (PZT). Some of experiences show that piezoelectric sensor can detect some defects, such as crack, thinning wall thickness, pitting corrosion, and others [2] [7] [8]. 
The polarization and principle of electromechanical coupling of piezoelectric material is the basis for using as sensors in real time monitoring, see figure 1 [9] [10].
Therefore, this paper discussed the possibility of a piezoelectric sensor application to monitor onshore pipelines with data of case study in section III.

TABLE 1

\begin{tabular}{cccc}
\multicolumn{4}{c}{ TYPICAL FREQUENCIES FOR PIPELINE MONITORING ACTIVITIES } \\
\hline $\begin{array}{c}\text { Aerial } \\
\text { surveillance }\end{array}$ & $\begin{array}{c}\text { Walking } \\
\text { survey }\end{array}$ & $\begin{array}{c}\text { Intelligent } \\
\text { inspection }\end{array}$ & $\begin{array}{c}\text { CP system } \\
\text { check }\end{array}$ \\
\hline 2 weeks & 4 years & $\begin{array}{c}\text { Max. 10 } \\
\text { years }\end{array}$ & $\begin{array}{c}\text { Max. 10 } \\
\text { years }\end{array}$ \\
\hline
\end{tabular}

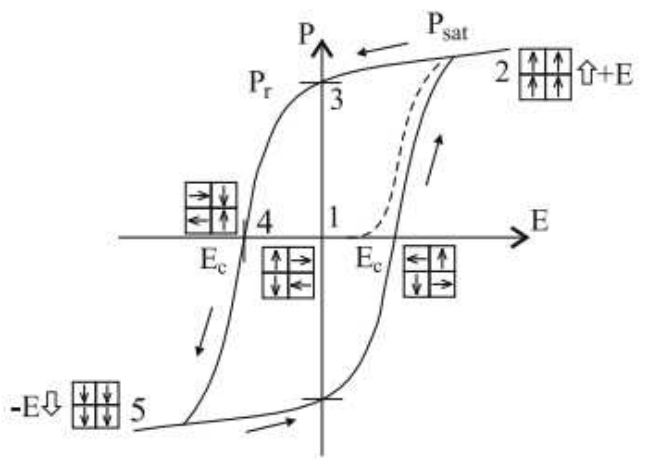

Figure 1. Hysteresis curve for polarization of piezoelectric material

\section{METHOD}

The previous research showed application of piezoelectric sensor to detect of metal damage Impedance based and Lamb wave propagation methods have been applied to the pipe for real-time monitoring. The experiment utilized the electromechanical effect on piezoelectric sensors from flexible Macro Fiber Composite (MFC) [9]. Application of piezoelectric for sensor also used for flexible ultrasonic transducer (FUT), which is made of PZT sol-gel composite with high sensitivity, adaptability and high temperature durability [11]. Others method to detect defect of pipeline were developed by Du Guofeng et.al, identification of crack damage in pipe structure using a stress wave propagation with piezoelectric transducers [2]. The wall thickness measurement using piezoelectric material sensor and electromechanical impedance (EMI) method has been applied with statistical method such as the root mean square deviation (RMSD). The principle is analyzing the variations of impedance from thinning of wall thickness by removing the plate one by one to simulate corrosion effect [8].

In this paper propose the concept of Impedancebased and Lamb wave propagation to monitor onshore pipeline in real time monitoring.

\section{- Impedance Method}

Piezoelectric material is utilized for real time monitoring. The effect of electromechanical coupling from piezoelectric material works to couple mechanical and electrical impedance. Representation of relationship between mechanical and electrical impedance in piezoelectric material which used to MFC patch is described by following formula [9].

$$
Y(\omega)=\frac{I}{V}=i \omega a\left(\bar{\varepsilon}_{33}{ }^{T}(1-i \delta)-\frac{Z_{s}(\omega)}{Z_{s}(\omega)+Z_{a}(\omega)} d_{3 x}^{2} \hat{Y}_{33}{ }^{E}\right)
$$

Where:

\begin{tabular}{|c|c|}
\hline$a$ & geometric constant of material of piezoelectric materials \\
\hline$d_{3 x}$ & sensor coupling constant at a neutral state \\
\hline$F(m, n)$ & $\begin{array}{l}\text { flexural non-axially symmetric modes with harmonic number of } \\
\text { circumferential variation and index counter }\end{array}$ \\
\hline$L(m, n)$ & longitudinal axially symmetric modes with index counter \\
\hline$T(m, n)$ & torsional axially symmetric modes with index counter \\
\hline$Y(\omega)$ & electrical admittance \\
\hline$Y_{x x}^{E}$ & complex Young's modulus with a zero electric field \\
\hline$Z_{a}$ & sensor mechanical impedance \\
\hline$Z_{s}$ & host structure mechanical impedance \\
\hline$\varepsilon_{33}^{T}$ & dielectric constant at a neutral state \\
\hline$\rho$ & Correlation coefficient \\
\hline$Z_{i, 1}$ & Baseline impedance data at frequency $i$ \\
\hline$Z_{i, 2}$ & Compared impedance atat at frequency $\mathrm{i}$ \\
\hline $\bar{Z}_{1}$ & Mean of signal \\
\hline$\sigma$ & Standard deviations \\
\hline
\end{tabular}

\section{- Lamb Wave Method}

The wavelengths on mechanical wave that have magnitude on the same order as thickness and as an infinite number of discrete modes are the principle of Lamb wave. The principle of lamb wave can be used to detect pipeline defect, such as corrosion in surface or internal structure of pipeline [9]. 


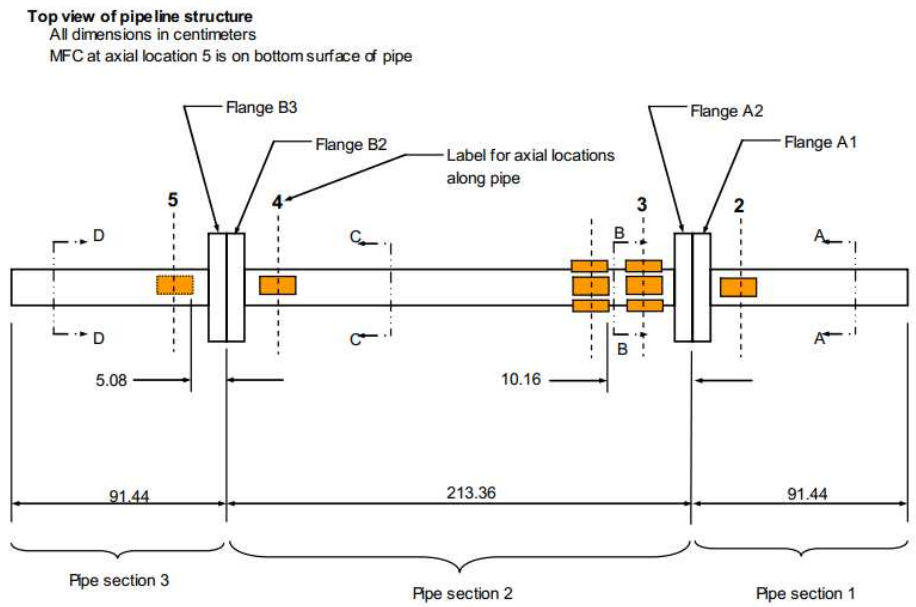

Figure 2. Dimensioned drawing of apparatus (Top view) [9]

Section A-A: Flange A1

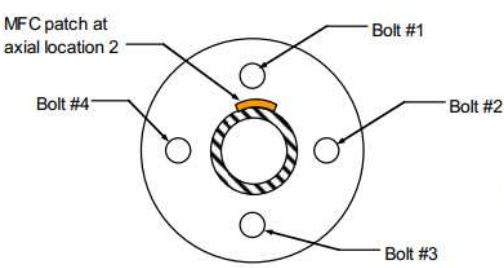

Section C-C: Flange B2

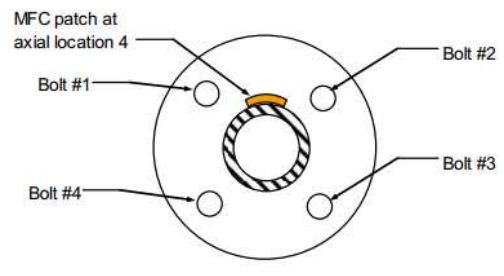

Section B-B: Flange A2

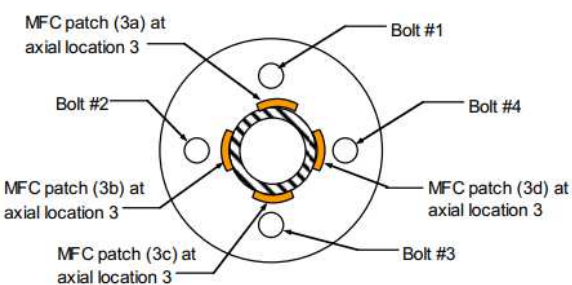

axial location 3

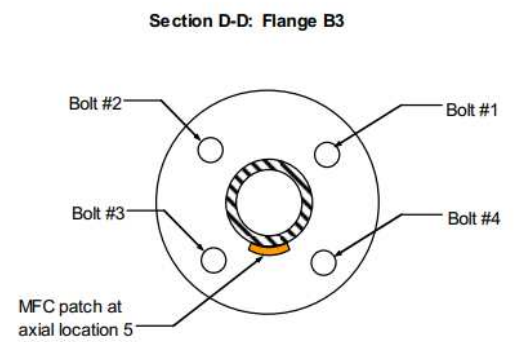

Figure 3. Dimensioned drawing of apparatus (cross sectional view) [9]

\section{RESULT AND DISCUSSION}

\section{A. Object Research}

The object of research is a pipeline along +3408 meters, with a nominal pipe diameter of 8 in. Basic data of the pipeline is as a follows:

$\begin{array}{ll}\text { Pipeline Service } & : \text { Crude Oil } \\ \text { Length } & : 3408 \text { meter } \\ \text { Year build } & : 1970 \\ \text { Design code } & : \text { ASME B31.4 } \\ \text { Nominal diameter } & : 8 \text { inch } \\ \text { Outside diameter } & : 8,625 \text { inch } \\ \text { Schedule } & : 40 \\ \text { Thickness } & : 8,18 \mathrm{~mm} \\ \text { Temperature design } & : 45^{\circ} \mathrm{C} \\ \text { Temperature operational } & : 38^{\circ} \mathrm{C} \\ \text { Pressure design } & : 360 \mathrm{psig} \\ \text { Max Operating Pressure } & : 100 \mathrm{psig} \\ \text { Specification of material } & : \text { API } 5 \mathrm{~L} \mathrm{Grade} \mathrm{B} \\ \text { SMYS } & : 35000 \mathrm{psi} \\ \text { Pigging facilities } & : \text { No }\end{array}$

Most pipeline construction is the aboveground pipeline, but there are several pipe segments that have burial conditions. The pipeline is in the plantation area and some of segments pass through residential area.

\section{B. Laboratory Scale Experiment}

The experiment on laboratory scale according research from Thien, et.al the apparatus is made from steel and consists of three section. Each section was connected using two flanged joints. The length of apparatus was 3.96 meter and each flanged joint has four bolts. The outside diameter of pipe was 2.5 inch and wall thickness 4.8 millimeters, see at figure 2 and figure 3. While the MFC patches have dimension 110 x 75 millimeters with active area 85 x 57 millimeters, see figure 4. [9].

There are three scenarios damage for experiment, the scenario damage describes the magnitude of damage in each case. For case 1, only one bolt removed from flange A. Case 2, two bolts removed from flange $\mathrm{A}$ and the same condition of case 2 applied 
in case 3 but the pipe rotated $180^{\circ}$. Therefore, case 3 is the most worst case scenario.

The experiment used the frequency $50-60 \mathrm{kHz}$. The specification of PZT which is used $320^{\circ} \mathrm{C}$ with relative dielectric constant 1200.

\section{Result of Laboratory Scale Experiment}

From the experiment, lamb waves and impedance methods produce the result in real monitoring.
The result from three scenarios damage can be shown in damage matrix [9]. From the figure 5, increasing damage metric was related with level of impedance damage. While in the figure 6 , the estimation of location and severity of surface damage in pipe are shown from wave attenuation and reflection.

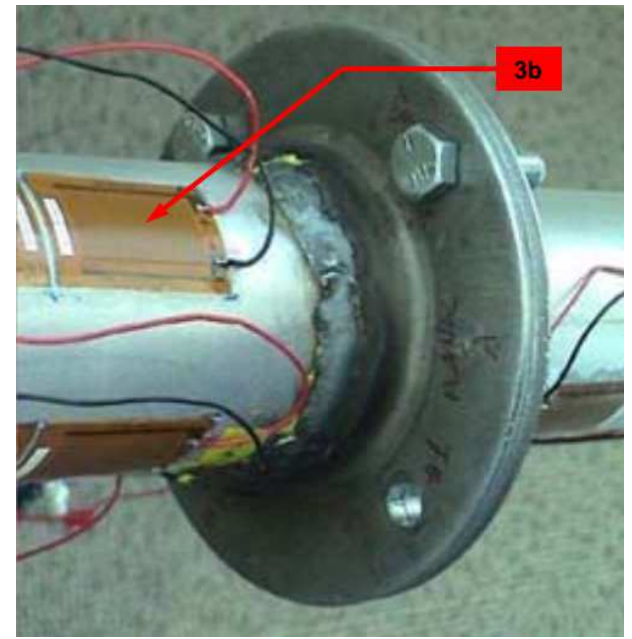

Figure 4. The example of MFC patch [9]
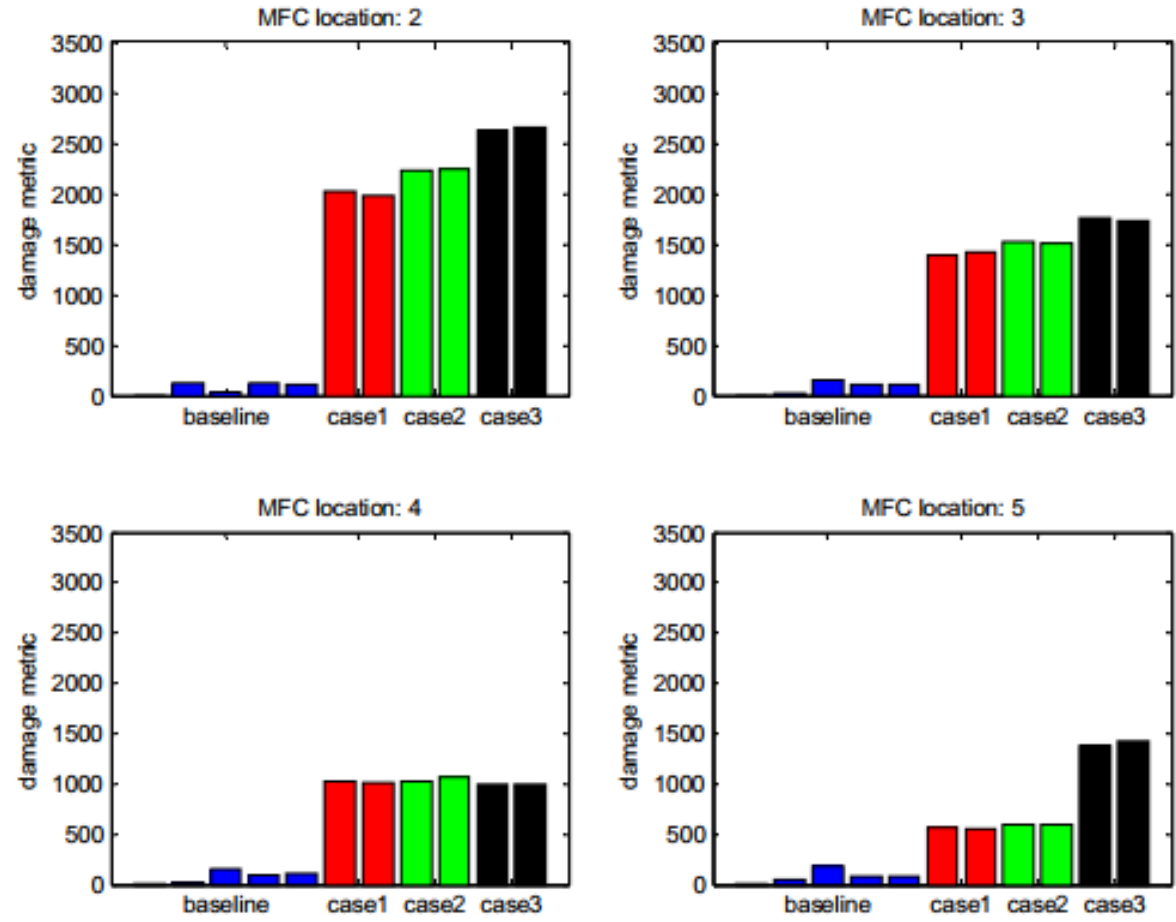

Figure 5. The damage metrics are representation of impedance damage [9] 


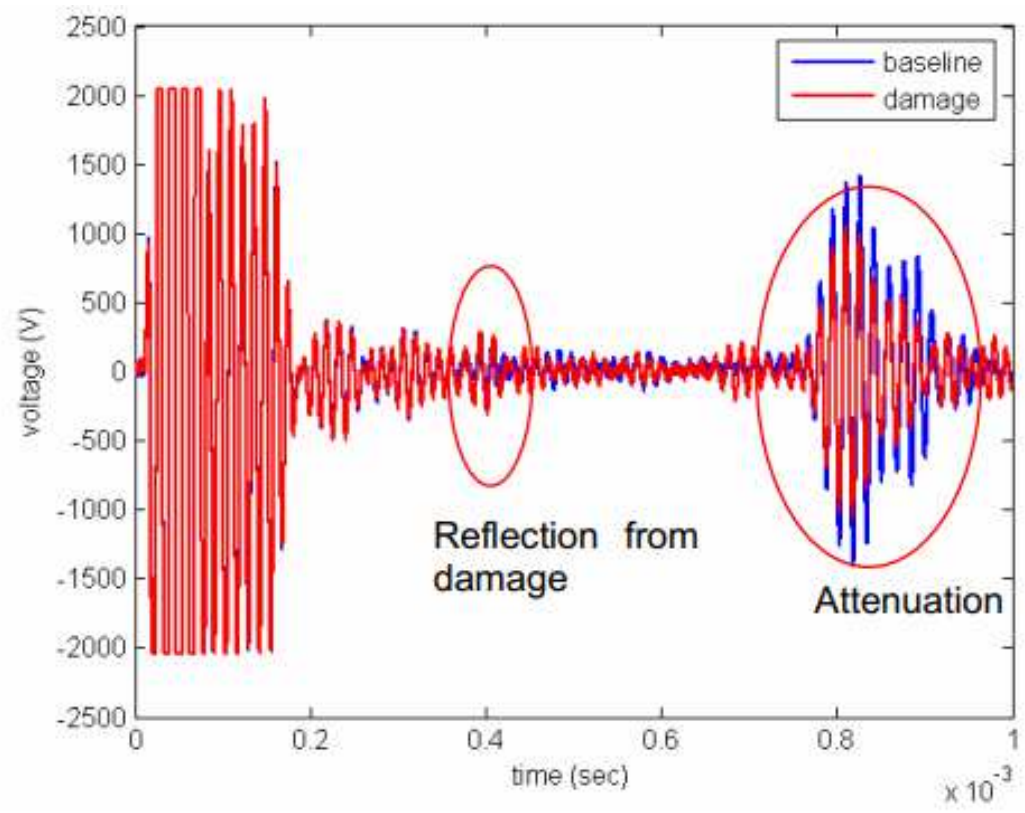

Figure 6. Damage and undamaged cases are shown from lamb waves [9]

D. Possibility Piezoelectric Sensor to Apply in Object Research (Scaling up)

The comparison among all methods of pipeline inspection, such as: walk survey, intelligent pigs, and structural health monitoring (SHM) in real time monitoring. The pipeline transported crude oil and operated during more than 20 years. The possibility of inspection methods that used for the pipeline are walk survey, however SHM. Intelligent pigs cannot be used for the pipeline due to the pipeline installation did not have pig launcher and receiver. In addition, nothing information about cleaning internal pipeline inspection during operation of pipeline. So, it can be assumed that a lot of waxy liquid sticks to the wall of the pipeline which can hinder the pigging tools.

Technical data of pipeline generally show that operational of pipeline is in range of capability piezoelectric sensor. Temperature operational of pipeline showed in $38^{\circ} \mathrm{C}$ with maximum design temperature $45^{\circ} \mathrm{C}$. Pipeline is manufactured from metal (API 5L grade B, SMYS 35000 psi), nominal diameter 8 inch. Piezoelectric sensor can detect some defects, such as: crack, thinning wall thickness, pitting corrosion, and others.

Consideration from research, scaling up of distance is maybe important. Distance for location of piezoelectric sensor effectively determine sensitivity of measurement defect between each sensor location. Application of piezoelectric sensor not only determine position of defect, but also can measure severity of damage estimation.

Although technically scaling up application of piezoelectric sensor based on operational pipeline can be applied, it is maybe necessary challenges to scaling up in real application are following:

1. Financial investment

Consideration of between revenue and investment cost and operational cost for maintenance. Some of segments of pipeline are in burial/underground, it needs high cost to dig the soil and apply piezoelectric sensor. According to research of Nozarian et.al structure health monitoring to detect defect can be applied for underground pipeline using piezoelectric sensor [12].

2. Human behavior surrounding pipeline area

As known that pipeline through residence are, near human activities. Without well public education in surrounding area, the human can make piezoelectric sensor facilities damage. In addition, from historical third-party damage report was founded that cathodic protection damage by human.

3. Receiving signal in long distance

The distance of pipeline may cause difficulties to receive signal from piezoelectric material (PZT) sensor. It becomes impractical to install piezoelectric sensor using cable for along pipe. The utilization of battery power combined with wireless sensing maybe is more practice to change the cable [13].

4. Protection of piezoelectric sensor

Piezoelectric sensor should be protected from damage, such as brittle due to environment conditions. The precaution to keep the sensor from excessive stresses and moisture is to add a layer of epoxy and silicone [14].

5. Future combination survey (Real Time Monitoring + Aerial)

Aerial survey possible to update some information every 2-4 weeks, such as right of way (ROW), population density. It is better if make combination with Structural Health Monitoring in real time condition, due to SHM focuses on structural pipeline to monitor defect and aerial survey focuses on environment surrounding pipeline. 


\section{CONCLUSION}

Many methods of pipeline inspection, such as: walk survey, intelligent pigs, and structural health monitoring (SHM). However, intelligent pigs cannot be used for the pipeline due to the pipeline installation did not have pig launcher and receiver. Furthermore, combination aerial survey and SHM are the most suitable for pipeline condition based on case study. Aerial survey possible to update some information every 2-4 weeks, such as: right of way (ROW), population density, whereas SHM focus on structural pipeline to leakage detection for short term and monitor defect for long term, such as: crack, thinning wall thickness, pitting corrosion, and others.

Technically scaling up application of piezoelectric sensor based on operational pipeline can be applied, it is maybe necessary challenges to scaling up in real application are following: 1. financial investment; 2 . human behavior surrounding pipeline area; 3 . receiving signal in long distance; 4. protection of piezoelectric sensor, 5. combination survey for future development.

\section{REFERENCES}

[1] International Monetary Fund (IMF) Report: April 2011

[2] Du, G., Kong, Q., \& Zhou, H, "Multiple cracks detection in pipeline using damage index matrix based on piezoceramic transducer-enabled stress wave propagation". Sensors. 2017. doi: $10.3390 / \mathrm{s} 17081812$

[3] D. Priyanta, N. Siswantoro, A. M. Megawan, "Risk Based Inspection of Gas-Cooling Heat Exchanger," International Journal of Marine Engineering Innovation and Research, Vol .1 (4), pp 317-329, Sept. 2017.

[4] D. Priyanta, N. Siswantoro, M. Saifulloh, "Scheduling Program Analysis of Pressure Relief Device (PRD) According to RBI API 581 on Production Gas Separator System," International Journal of Marine Engineering Innovation and Research, Vol. 3 (1), pp 1-7, Dec .2018.

[5] Alkazraji, D., "A quick guide to pipeline engineering. Cambridge," England: Woodhead Publishing Limited, 2008.

[6] Duan, W. H., Wang, Q., \& Quek, S. T, "Applications of piezoelectric materials in structural health monitoring and repair: Selected research examples," Materials, 2010, doi: 10.3390/ma3125169

[7] Tua, P. S., Quek, S. T., \& Wang, Q, "Detection of cracks in cylindrical pipes and plates using piezo-actuated Lamb waves," Smart Materials and Structures, 2005, doi:10.1088/09641726/14/6/025

[8] Na, W. S. "Possibility of detecting wall thickness loss using a PZT based structural health monitoring method for metal based pipeline facilities" NDT and E International, 2017, doi:10.1016/j.ndteint.2017.03.001

[9] Thien, A. B., Chiamori, H. C., Ching, J. T., Wait, J. R., \& Park, G, "Piezoelectric Active Sensing for Damage Detection in Pipeline Structures," 2005.

[10] Sunar, M. "Piezoelectric Materials," In M. Sunar, Comprehensive Energy Systems, 2018, doi:10.1016/B978-012-809597-3.00248-0

[11] Wu, T. C., Kobayashi, M., \& Tanabe, M, "The use of flexible ultrasound transducers for the detection of laser-induced guided waves on curved surfaces at elevated temperatures," Sensors, 2017, doi:10.3390/s17061285

[12] Nozarian, M. M., Adeldost, H., \& Zabihollah, A, "Crack detection in underground pipelines using piezoelectric sensors," Advanced Science Letters, 2013, doi:10.1166/asl.2013.4844

[13] Golshan, M., Ghavamian, A., Mohammed, A., \& Abdulshaheed, A, "Pipeline Monitoring System by Using Wireless Sensor Network," IOSR Journal of Mechanical and Civil Engineering (IOSR-JMCE), 13(3), 43-53, 2016, doi:10.9790/1684-1303054353

[14] Zhu, J., Ren, L., Ho, S. C., \& et.al, "Gas pipeline leakage detection based on PZT sensors," Smart Materials and Structure, 2017, doi:10.1088/1361-665X/26/2/025022 